\title{
Group predictions of item differences of CVC trigrams
}

LOUIS G. LIPPMAN and B. L. KINTZ, Department of Psychology, Western Washington State College, Bellingham. Wash., 98225

Two groups of Ss ranked $20 \mathrm{CVC}$ trigrams, which represented the full range of meaningfulness values according to established norms, for either pronunciability or ease of learning. and then recalled the trigrams incidentally. Two additional groups learned the trigrams by free learning and then ranked the trigrams for either pronunciability or ease of learning. Correlations between mean ranks, group learning measures, and meaningfulness were fairly high (median $r=.75$ ), in keeping with recently reported findings.

Underwood (1966) recently reported that group scale values obtained from ratings of item difficulty, association value, and pronunciability all predicted intentional free learning and incidental recall with considerable accuracy (average correlation was approximately .90) Underwood's materials. however, consisted of 27 trigrams which varied considerably in structure - from zero to two vowels were present in each of the items-and included both low-meaningful consonant trigrams as well as common three-letter words. Since structural variability of material may have served to enhance Ss' ability to differentiate between items which were more or less difficult to learn or pronounce, the present experiment repeated Underwood's study with a list of 20 trigrams which were homogeneous in structure. The second main difference between the present study and Underwood's experiment was that stimulus presentation for free learning was visual rather than auditory.

\section{SUBJECTS}

The Ss were 42 students from four laboratory sections of an experimental psychology and statistics course at Western Washington State College. All Ss had completed an introductory psychology course, hut had no training in experimental psychology.

MATERIALS

Twenty CVC trigrams from Archer's (1960) norms were selected at $5 \%$ increments in meaningfulness and ranged from 2 to $97 \%$ inclusive. Intralist similarity was minimized by ensuring that the first letter of each trigram started with a different consonant. An attempt to minimize repetition among the third letters of each trigram resulted in representation of all consonants except $G$ and $P$ and one repetition each of $R$ and $Z$. The letter " $Y$ " was excluded entirely from the list. Inevitable repetition among vowels ranged from two occurences $(O)$ to six occurrences (l). PROCEDURE

Each of four groups performed a ranking task and a learning task.

Group 1: Ten Ss first ranked the trigrams according to pronunciability; then, following the ranking task, the Ss were handed a blank sheet of paper and instructed to write down as many of the trigrams as they could recall. For the ranking task, Ss were given an envelope containing twenty $2 \times 2$ in. cards. Each of the 20 CVCs was typed in the center of each of the cards. The sequence of the cards within each of the envelopes was random. The instructions used by Underwood \& Schulz (1960) were adapted to a ranking procedure. The Ss were instructed to arrange the cards in a row from the trigram which "a person would find most difficult to pronounce" to the combination which "a person would find easiest to pronounce." The Ss were instructed to then stack the cards so that the most easily pronounced item was on top and the most difficult item was on the bottom; and, finally, to place the empty envelope on top of the stack. Following incidental recall, the numbers 1 through 20 were assigned to each of the ranked trigrams such that one represented the trigram $S$ judged as easiest and 20 the trigram ranked most difficult to pronounce.

Group 2: Eleven Ss first ranked the trigrams according to ease of learning; then, following the ranking task, the Ss were tested tor incidental recall as described for Group 1. The instructions and procedure used by Underwood for magnitude estimation of ite'm difficulty were adapted to a ranking procedure. Envelopes containing cards in random orders were used as in Group 1. The Ss arranged the trigram cards from the syllable which would be most difficult for "a person" to learn to the trigram which they judged

Table 1

Trigrams, Meaningfulness Values, Mean Scores for Incidental Recall and Free Learning, and Mean Ranks for Pronunciability and Ease of Learning

\begin{tabular}{|c|c|c|c|c|c|c|c|c|c|}
\hline \multirow[b]{2}{*}{ 疍 } & \multirow[b]{2}{*}{ 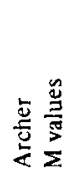 } & \multicolumn{2}{|c|}{ Group 1} & \multicolumn{2}{|c|}{ Group 2} & \multicolumn{2}{|c|}{ Group 3} & \multicolumn{2}{|c|}{ Group 4} \\
\hline & & 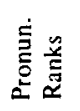 & 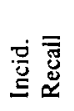 & 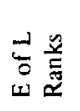 & 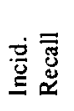 & 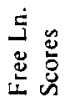 &  &  & 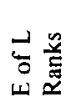 \\
\hline BUK & 77 & 8.80 & 0.70 & 6.64 & 0.55 & 6.73 & 6.00 & 6.80 & 8.30 \\
\hline CIR & 82 & 9.70 & 0.90 & 8.82 & 0.82 & 6.73 & 8.36 & 8.20 & 5.70 \\
\hline DAS & 72 & 5.70 & 0.80 & 4.82 & 0.91 & 7.18 & 5.91 & 5.90 & 11.70 \\
\hline FUT & 62 & 9.30 & 0.60 & 6.73 & 0.55 & 8.18 & 7.91 & 7.40 & 7.90 \\
\hline GOW & 42 & 8.60 & 0.80 & 9.55 & 0.18 & 7.64 & 9.27 & 7.30 & 7.70 \\
\hline HON & 97 & 6.20 & 0.80 & 0.64 & 0.64 & 7.09 & 4.64 & 8.30 & 3.50 \\
\hline JUC & 37 & 13.70 & 0.60 & 12.82 & 0.36 & 5.18 & 13.91 & 5.20 & 13.00 \\
\hline KIL & 92 & 2.90 & 0.90 & 2.64 & 1.00 & 8.18 & 2.00 & 8.90 & 2.50 \\
\hline LEH & 52 & 12.30 & 0.90 & 11.73 & 0.04 & 6.55 & 13.45 & 6.50 & 10.20 \\
\hline MIB & 27 & 8.40 & 0.70 & 9.27 & 0.45 & 5.64 & 9.36 & 5.80 & 11.70 \\
\hline NIJ & 7 & 13.70 & 0.40 & 17.27 & 0.18 & 4.45 & 14.64 & 5.60 & 14.00 \\
\hline PIM & 57 & 5.90 & 0.50 & 7.55 & 0.36 & 7.09 & 0.36 & 7.40 & 7.90 \\
\hline QEV & 12 & 17.40 & 0.30 & 17.45 & 0.27 & 4.00 & 17.64 & 4.90 & 18.00 \\
\hline RAX & 47 & 10.60 & 0.60 & 9.36 & 0.36 & 6.00 & 11.45 & 5.30 & 11.80 \\
\hline SER & 87 & 7.60 & 0.90 & 5.36 & 0.82 & 7.00 & 0.00 & 7.50 & 6.20 \\
\hline TLH & 32 & 12.40 & 0.90 & 13.64 & 1.00 & 0.09 & 13.91 & 7.20 & 10.30 \\
\hline VUD & 22 & 12.60 & 0.60 & 13.27 & 0.45 & 5.45 & 11.45 & 4.80 & 15.20 \\
\hline WUF & 67 & 0.30 & 0.20 & 9.27 & 0.36 & 5.27 & 10.45 & 5.20 & 9.90 \\
\hline$X \wedge Z$ & 2 & 18.60 & 0.50 & 18.55 & 0.36 & 5.18 & 19.55 & 5.10 & 16.60 \\
\hline $\mathrm{ZlQ}$ & 17 & 16.80 & 0.40 & 18.45 & 0.27 & 5.09 & 17.73 & 4.10 & 17.90 \\
\hline
\end{tabular}


Table 2

Intercorrelations Among All Learning Measures and Scale Values

\begin{tabular}{|c|c|c|c|c|c|c|c|c|c|}
\hline \multirow[b]{2}{*}{$\begin{array}{l}\text { Groups and } \\
\text { Conditions }\end{array}$} & \multicolumn{2}{|c|}{ Group 1} & \multicolumn{2}{|c|}{ Group 2} & \multicolumn{2}{|c|}{ Group 3} & \multicolumn{2}{|c|}{ Group 4} & \\
\hline & த் & 疍震 & 焉 & 远 局 & 点 & 官 &  & $\begin{array}{l}3 \\
0 \\
4\end{array}$ & 总 \\
\hline Archer $\mathbf{M}$ & -.83 & .54 & -.90 & .63 & .76 & -.88 & .76 & -.89 & .77 \\
\hline Pron. (1) & - & -.42 & .94 & -.48 & -.75 & .95 & -.68 & .84 & .74 \\
\hline Incid. Recall (1) & - & - & -.55 & .75 & .68 & -.53 & .71 & -.64 & .60 \\
\hline$E$ of $L(2)$ & - & - & - & -.58 & -.84 & .96 & -.72 & .85 & .79 \\
\hline Incid. Recall (2) & - & - & - & - & .55 & -.54 & .62 & -.57 & .59 \\
\hline Free Learning (3) & - & - & - & - & - & -.81 & .82 & -.83 & .76 \\
\hline Pron. (3) & - & - & - & - & - & - & -.76 & .87 & .79 \\
\hline Free Learning (4) & - & - & - & - & - & - & - & -.93 & .75 \\
\hline E of L (4) & - & - & - & - & - & - & - & - & .80 \\
\hline
\end{tabular}

"a person would learn most quickly." The cards were then stacked and concealed as in Group 1. Following incidental recall, the number 1 was assigned to the item judged easiest and 20 to the item ranked as most difficult to learn.

Group 3: Eleven Ss leamed the 20 trigrams by free learning (in two independent subgroups of five and six Ss each), then ranked the syllables for pronunciability according to the procedure described for Group 1. The procedure for free learning corresponded closely to Underwood's free learning task except presentation was visual rather than auditory. Trigrams printed on index cards were shuffled into a random sequence, then presented manually at a $2 \mathrm{sec}$ rate. Following each of the 10 presentation trials, Ss wrote as many syllables as they could recall onto successive pages of prepared 10-page booklets.

Group 4: Ten Ss first learned the trigrams by free learning (in two subgroups of five Ss each), as described for Group 3, then ranked the syllables for ease of learning according to the procedure described for Group 2. Since this group had participated in free learning prior to the ranking task, it was not necessary to describe the hypothetical learning task in as much detail as was necessary for Group 2 . The instructions for ranking were abbreviated accordingly.

\section{RESULTS AND DISCUSSION}

Mean rank values and mean learning scores are presented in Table 1. Some major comparisons of interest among these values are initial pronunciability ranks (column 2) vs initial ease of learning ranks (column 4) and vs pronunciability ranks following free learning (column 7); and ease of learning rankings before vs after free learning (columns 4 and 9, respectively). The two incidental recall measures show no reliable differences in either means or variances. The means and variances of the two free learning groups also do not differ.

The intercorrelations among all the measures in Table 1 are presented in Table 2 . It should be noted that the negative correlations are due to the assignment of the value " 1 " as the highest rank for the pronunciability and ease of learning measures. Although the correlation values are not as uniformly high as were those reported by Underwood, all the rs differ significantly from zero $(p<.05)$.

Pronunciability. Irrespective of whether the trigrams were ranked for pronunciability initially or following 10 free learning trials, the two mean rankings of pronunciability are quite consistent $(r=.95)$. Correlations between pronunciability and mean learning scores indicate two minor, but consistent, relationships: (1) Pronunciability rankings obtained after a learning task has been completed correlate slightly higher with all learning measures than do those pronunciability rankings which were obtained as S's initial task (the correlations for initial are $-.42,-.44,-.75$, and -.68 ; whereas the correlations for after learning are $-.53,-.47,-.81$, and -.76 ); and (2) the intentional learning measures are more highly correlated with pronunciability ranks than are the incidental recall measures, regardless of whether the ranking was performed initially or following a learning task (the mean correlation with intentional learning is -.75 whereas the mean for incidental recall is -.49).

Ease of learning. The correlation between the two measures of ease of learning is .85 , which is somewhat lower than the correlation between the two measures of pronunciability. A possible reason for this reduced relationship between ease of learning measures is that the abstract concept of "ease of learning" is not as definitively constituted as "pronunciability." A S can test relative pronunciability of trigrams directly, by covert pronunciation of the trigrams, whereas direct determination of "ease of learning" is not possible in the absence of a learning or recall task.

The differences between correlations of pronunciability rankings which were obtained initially and following free learning, and the differences between correlations of intentional free learning and incidental recall which were reported above for pronunciability rankings, are also present in the ease of learning ranks: (1) The mean correlation between ease of learning ranks taken initially and the four recall measures is -.67 , but when the ease of learning rankings were made after learning the mean correlation is -.74 ; and (2) the mean correlation between incidental learning and the ease of learning ranks is -.58 , but the mean correlation between free learning and ease of learning ranks is -.83 . The highest correlation between ease of learning ranks and learning measures occurs between free learning and subsequent ease of learning rankings within Group $4(r=.93)$. Thus, completion of, or exposure to an empirical test of item difficulty (free learning) permits Ss to judge accurately the ease with which the items might be learned, in keeping with the differences suggested between the concepts of pronunciability and ease of learning.

General relationships. Mean correlations for each of the nine sets of scores, which are presented in the far right column of Table 2 , indicate that the ease of learning rankings made after completion of the learning task correlate highest overall with the other scores $(r=.80)$. The next highest mean relationships with all other sets of scores are initial ease of learning ranks $(r=.79)$ and pronunciability ranks obtained following learning $(r=.79)$.

The present findings of substantial relationships between group ratings and performance in free learning and incidental recall are in essential agreement with results reported by Underwood. The high mean correlation $(r=.77)$ between Archer's meaningfulness values and measures collected in the present experiment is of interest since these measures were collected neither concurrently nor from samples from the same population. The present results thus suggest a general meaningfulness concept which may underlie such factors as pronunciability, ease of learning, and rated meaningfulness; and which effectively predicts performance, particularly in the presence of instructions to learn.

\section{REFERENCES}

ARCHER, E. J. A re-evaluation of the meaningfulness of all possible CVC trigrams. Psychological Monographs, 1960, 74, No. 10 (Whole No. 497).

UNDERWOOD, B. J. Individual and group predictions of item difficulty for free learning. Journal of Experimental Psychology, 1966, 71, 673-679.

UNDERWOOD, B. J., \& SCHULZ, R. W. Meaningfulness and verbal learning. Philadelphia: Lippincott, 1960. 